\title{
THE INFLUENCE OF INFANT'S EXPOSURE TO THIMEROSAL CONTAINING VACCINES ON THE DEVELOPMENT IN THE FIRST THREE YEARS OF LIFE
}

\author{
D. Mrozek-Budzyn, R. Majewska, A. Kieltyka, M. Augustyniak, E. Mroz, A. Skarupa
}

Chair of Epidemiology and Preventive Medicine, Jagiellonian University Medical College, Krakow, Poland

Background and aims: The controversial topic of the early human exposure to mercury compounds is ethylmercury, which is present in the thimerosal-containing vaccines (TCV). The objective of this analysis was to determine the relationship between the infant's exposure to TCV and cognitive and psychomotor development of children during the first 3 years of life.

Methods: The cohort recruited prenatally in Krakow, Poland, included 310 children vaccinated against hepatitis-B, diphtheria, tetanus and pertussis using formula with or without thimerosal. The children development was assessed using the Bayley Scales of Infant Development BSID-II $\left(12^{\text {th }}, 24^{\text {th }}\right.$ and $36^{\text {th }}$ month). Data were analyzed by multivariable linear and logistic regression, adjusted to potential confounders.

Results: Children exposed to TCV during the first year of life had lower psychomotor BSID-II scores at $12^{\text {th }}$, $24^{\text {th }}$ and $36^{\text {th }}$ month of life than those vaccinated without TCV $(\beta=-4.4, p=0.479 ; \beta=-13.8, p=0.014, \beta=-1.4$, $\mathrm{p}=0.812$ respectively). The risk of the delayed psychomotor development as well as results of the mental developmental tests were not associated with the TCV-related exposure. Results were similar when we analyzed exposure to TCV during first two years of life.

Conclusions: Our study demonstrated that TCV administration in two first years of life was associated with significantly lower infants' psychomotor scores only in $24^{\text {th }}$ month of life. However, TCV did not have an influence on children's cognitive development.

All studied children were a sample from cohort study on the susceptibility of fetus and child to environmental factors followed in Krakow with Columbia University in New York. 